\title{
Self reported poor health and low educational level predictors for mortality: a population based follow up study of 39156 people in Sweden
}

\author{
Jan Sundquist, Sven-Erik Johansson
}

\begin{abstract}
Objective - To analyse the relative risk (RR) of mortality for people who reported poor health or had low educational level. Setting - Sweden.

Design - A random sample of 39156 people was interviewed face to face by Statistics Sweden from 1979-85. The dependent variable was total mortality. Independent variables were sex, age, marital status, and socioeconomic position, defined as educational level, type of housing tenure, and health status. This study was designed as a follow up study ranging from 1 January 1979 to 31 December 1993. Information on the dependent variables was obtained from the central cause of death register. $\mathrm{Re}$ spondents were linked to the register by the Swedish personal registration number. Person-years at risk were calculated from the date of the interview until death, or for those who survived, until the end of the follow up period. Data were analysed in relation to gender and age (25-59 years and $60-74$ years) in a proportional hazard model in order to estimate $R R$.
\end{abstract}

Results - During follow up 2656 men and 1706 women died. Men and women in both age groups who reported poor health status at the interview had a strongly increased risk of dying during the follow up period $(R R=2.05$ (95\% confidence interval 1.72 , 2.31) and $R R=1.91(1.74,2.10)$ for men, and $R R=2.34(1.94,2.83)$ and $R R=1.80$ $(1.61,2.02)$ for women for the younger and older age groups respectively) when simultaneously controlled for age, marital status, education, and housing tenure. Living alone, renting an apartment, and low educational level ( $\leq 9$ years) were also associated with increased mortality risks for men and women in both age groups.

Conclusion - Poor self reported health was a strong predictor for total mortality. Furthermore, in Sweden, a country well known for the equality of its income distribution, there are inequalities in health with higher total mortality risks for people with a low educational level and those who are not owner-occupiers.

(f Epidemiol Community Health 1997;51:35-40)

Morbidity data are an important complement to mortality data. When life expectancy in- creases, chronic disorders are likely to be more prevalent. Many diseases today, such as musculoskeletal disorders, are not necessarily fatal, but are common among workers in occupations that make tough physical demands, causing much suffering for unhealthy workers. ${ }^{1}$ It may be that the lifelong experience of health and illness most clearly shows the difference between social groups. The measurement of morbidity is difficult, and the only way to obtain information about subjective health (illness) is to use surveys. There is a tradition in the UK, Sweden, and the USA of conducting this type of survey. The same questions have, to a large extent, been used in all these surveys, eg the first Swedish level of living survey from 1968, the American health interview surveys, the British general household survey, and the Swedish annual level-of-living surveys. The Swedish annual level-of-living survey (SALLS) is a nationwide, systematic random sample of about 8000 individuals aged $16-84$. The purpose is to collect data on the individual level with the objective of obtaining an analysis of the distribution of economic resources, health status, and various aspects of the social and work environment in the Swedish population. ${ }^{2}$ The questions were designed to provide objective data about living conditions in the Swedish population. In an analysis of living conditions for 1975-85, SALLS showed clear differences in health between manual workers and civil servants/officials. ${ }^{3}$ There was, however, a tendency to narrowing of class inequality, especially as regards disability.

The British general household survey (GHS), based on a random sample of about 12000 households each year and with around 25000 subjects, included items relating to long standing illness and acute illness (period prevalence) (Office of Population Censuses and Surveys 1986). The health and lifestyle survey, a random sample of 9000 people aged 18 and over, included some questions similar to those from the GHS, but also some simple clinical tests of lung function, blood pressure, height, and weight. Between 1971 and 1976, the rate of self reported long standing illness (GHS) was three times greater among unskilled workers than among professionals. ${ }^{4}$ Blaxter, ${ }^{5}$ who used self reported data from the health and lifestyle survey, found a steep and regular trend toward more frequent illness in manual classes at every age for women and for all but the youngest men. ${ }^{5}$ Lower occupational classes ex- 
perienced more long standing and incapacitating illness than higher classes, according to Whitehead. ${ }^{6}$ Data from the general household surveys showed that the difference in the prevalence of long term illness between manual and non-manual groups increased between 1980 and 1988 (Office of Population Censuses and Surveys 1990). Clear class gradients existed for the most commonly reported causes of long term illness - for musculoskeletal, respiratory, and circulatory disorders. Delamothe, ${ }^{7}$ deputy editor of the British $\mathrm{Med}$ ical fournal, has commented on the class differences in morbidity: "Less privileged groups therefore not only have a shorter life span, but also spend more of their lives in poor health."

Inequalities in health status between social groups in Sweden as measured by health care utilisation, conventional indicators of perceived health status and long term illness, premature mortality, and mortality showed clear socioeconomic gradients in health status. ${ }^{8-11} \mathrm{~A}$ recently published study from Statistics Finland showed that mortality differences in relation to social class have not decreased during the past decade. ${ }^{12}$

In a Swedish study of 989 middle aged men followed up for 9 years, self rated poor health at baseline in 1973 was a significant risk factor for mortality. ${ }^{13}$ We believe that the rating of a person's global health status is the result of something very deep within the personality and of a long standing consciousness about their health. Therefore, self rated health is an important dimension of illness-subjective il health. Furthermore, we argue that there has to be an association between illness and disease (objective ill health). Mortality is a good measure of objective ill health. Therefore, self rated poor health must be a good predictor of mortality. We emphasise that analysing the relation between self rated health and mortality is not new. However, the new feature of the present study is the focus on self rated health in such a large sample of the Swedish population almost 40000 people, followed over 14 years. The large size of the sample allows separate analyses for men and women, and the power of the study permits more detailed analyses.

The first aim of this study was to analyse whether self reported poor health influences total mortality when simultaneously controlling for age, marital status, type of housing tenure, and education. The second aim was to analyse the influence of socioeconomic position, operationalised as the level of educational attainment and type of housing tenure, on total mortality.

\section{Method}

SALLS is based on face to face interviews with a nationwide random sample of approximately 8000 people per year. The present study contains information from 39156 respondents aged from 25 to 74 years. The data were collected over a seven year period from 1979-85 and the respondents constituted seven independent random samples of the Swedish population. The interviews generally took place in the respondents' homes and the response rate was on average $84.6 \%$.

The present study was designed as a follow up study ranging from 1 January 1979 to 31 December 1993. Information on the dependent variable was obtained from the central cause of death register. Respondents were linked to this register by the Swedish personal registration number.

Person-years at risk were calculated from the date of the interview until death, or for those who survived, until the end of the follow up period.

Four independent variables, apart from sex and age, were defined as follows:

1. Marital status - this variable was dichotomised into those who were married or cohabiting and those who were living alone.

2. Socioeconomic position - defined in terms of the level of educational attainment. The respondents were classified into three groups: (a) primary school ( $\leq 9$ years); (b) completed, at most, two years of high school (10-11 years); (c) completed more than two years of high school or university studies (>11 years).

3. Socioeconomic position - defined in terms of the type of housing tenure. This was dichotomised into those who lived in rented flats and all others.

4. Health status - the clients were asked, "How would you describe your general health?" There were three response alternatives: good, bad, or anywhere between good and bad. Those who answered that their health status was bad or anywhere between good and bad were considered to be ill.

\section{STATISTICAL METHOD}

The data were analysed by a proportional hazard model, ${ }^{14}$ by sex and age (25-59 and 60-74 years), in order to estimate the relative risks (RR) of total mortality. The RR can be expressed as the ratio of the hazard functions between two groups and is calculated by exponentiating the regression coefficient. The results are presented as $\mathrm{RR}$ with $95 \%$ confidence intervals (CI). As a measure of improvement in model fit, when including a covariate, the change in $-2 \log$ likelihood was used. The proportional hazards assumption was analysed by inspecting $\log (-\log )$ survival curves for parallelism. All included variables approximately met the assumption. We have tested one more social variable, poor social network, which showed no association with mortality in any model when controlled for the other variables in proportional hazard model. First order interactions were simultaneously tested in each of the four models. In order to avoid age interactions, the data were analysed in two age groups. Age was included as a continuous variable in all models shown in table 4 . There were two other interactions, one in each of the models for men (age*marital status, $p=0.008$ ) and women (age* health status, $p=0.004$ ) in age $25-59$ years. None of these models was significantly better than the 
Table 1 Distribution of the independent variables in relation to sex and age (\%) and the number of individuals in each group (no)

\begin{tabular}{|c|c|c|c|c|c|c|c|}
\hline \multirow[b]{2}{*}{ Variable } & \multirow[b]{2}{*}{ Level } & \multicolumn{3}{|l|}{ Men } & \multicolumn{3}{|l|}{ Women } \\
\hline & & $25-44$ & $45-59$ & $60-74$ & $25-44$ & $45-59$ & $60-74$ \\
\hline Marital status & Living alone & 27.0 & 21.5 & 23.2 & 21.1 & 22.1 & 41.4 \\
\hline Years of & $<=9$ & 25.6 & 45.8 & 60.8 & 26.7 & 51.9 & 67.9 \\
\hline \multirow{2}{*}{ education } & $10-11$ & 32.0 & 24.6 & 19.7 & 38.7 & 30.4 & 23.1 \\
\hline & $>11$ & 42.4 & 29.6 & 19.5 & 34.6 & 17.7 & 9.0 \\
\hline Housing tenure & Renting & 38.2 & 28.1 & 33.1 & 34.8 & 29.2 & 39.3 \\
\hline Health status & Bad & 12.2 & 28.1 & 41.3 & 13.5 & 30.4 & 45.5 \\
\hline No & & 9564 & 5061 & 4684 & 9562 & 5268 & 5017 \\
\hline
\end{tabular}

main effect model and two interactions can be expected by chance, so they were not included in the final models. Time was defined as years from interview until death or until censoring at the end of the follow up period. The expected number of deaths was calculated from life tables for the decade $1981-90 .^{15}$

\section{Results}

The distribution of independent variables in relation to sex and in three different age groups 25-44, 45-59, and 60-74 years are presented in table 1 . About $41 \%$ of the women aged 60 to 74 years lived alone, while the percentages for the other age groups in both sexes varied between 21 and $27 \%$. The proportion of low educational groups increased with increasing age. The type of housing tenure was about equally distributed in all age groups (table 1).

The present study is based on 435530 person-years at risk. During the follow up period 2656 men and 1706 women died. The observed number of deaths during the follow up period was about the same as expected, (2777 and 1722 respectively) calculated from life tables for the decade 1981-90.

Bad health status was associated with crude relative mortality risks varying between 1.98 and 3.54 for men (table 2) and between 1.89 and 3.78 for women (table 3 ). There was a clear gradient between educational status and the RR of mortality in all strata and for both sexes. Single living was associated with high crude RR for both men and women in all ages, with RR between 1.43 and 1.79 (table 2 and 3 ). The type of housing tenure was also associated with high crude $R R$.

Poor health status was a significant risk factor for death for men and women aged 25 to 59 with RR $2.05(1.72,2.31)$ and $2.34(1.94,2.83)$ respectively when simultaneously controlled for age, marital status, educational status, and form of tenure (table 4). Both men and women aged 60 to 74 years who reported bad health also had high RR. There was a graded, but weak association between educational status and mortality, particularly at ages 25 to 59 years. Low educational level of attainment ( $\leq 9$ years) for men and women aged 25 to 59 years was associated with increased mortality, with $R R$ of $1.20(1.01,1.43)$ and $1.42(1.07,1.88)$ respectively when controlled for the other variables in the proportional hazard models. The association between the middle educational level (10-11 years) of attainment and mortality was on a lower level and showed a non-significant tendency to an increased RR of 1.13 for men and 1.30 for women. Men and women aged 60-74 years with $\leq 9$ years of education had increased RR of $1.17(1.03,1.34)$ and 1.33 $(1.05,1.68)$ respectively. The other social class variable, type of tenure, was related to an augmented mortality risk at all ages and in both sexes when simultaneously controlled for age, marital status, educational status, and health status (table 4).

The crude $R R$ of low educational attainment ( $\leq 9$ years) and bad health status decreased strongly for men and women aged 25-59 years when controlled for all other variables simultaneously (tables 2-4). The crude RR for renting and single living were approximately the same in the final model. Among people

Table 2 Number of individuals (no), number of deaths (d), crude relative risk (RR) with $95 \%$ confidence interval (CI) for each independent variable in relation to age in men

\begin{tabular}{|c|c|c|c|c|c|c|c|c|c|}
\hline \multirow[b]{2}{*}{ Variable } & \multirow[b]{2}{*}{ Level } & \multicolumn{4}{|l|}{$25-59 y$} & \multicolumn{4}{|c|}{$60-74 y$} \\
\hline & & No & $d$ & $R R$ & $95 \% C I$ & No & $d$ & $R R$ & $95 \% C I$ \\
\hline \multirow[t]{2}{*}{ Marital status } & Living alone & $\begin{array}{r}3269 \\
1136\end{array}$ & $\begin{array}{l}259 \\
553\end{array}$ & 1.79 & $(1.55,2.08)$ & $\begin{array}{r}974 \\
3710\end{array}$ & $\begin{array}{r}495 \\
1369\end{array}$ & 1.67 & $(1.51,1.85)$ \\
\hline & Marned/conabitung & & & & & & & & \\
\hline \multirow{2}{*}{$\begin{array}{l}\text { Years of } \\
\text { education }\end{array}$} & $<=9 \mathrm{y}$ & 4823 & 387 & 2.17 & $(1.83,2.58)$ & 2876 & 1241 & 1.44 & $(1.27,1.64)$ \\
\hline & $\begin{array}{l}10-11 y \\
<11 y\end{array}$ & $\begin{array}{l}4291 \\
5511\end{array}$ & $\begin{array}{l}202 \\
203\end{array}$ & 1.30 & $(1.07,1.57)$ & $\begin{array}{l}911 \\
897\end{array}$ & $\begin{array}{l}342 \\
281\end{array}$ & 1.28 & $(1.09,1.50)$ \\
\hline \multirow{4}{*}{$\begin{array}{l}\text { Housing } \\
\text { tenure } \\
\text { Health status }\end{array}$} & Renting & 4936 & 325 & 1.36 & $(1.18,1.57)$ & 1520 & 713 & 1.39 & $(1.26,1.52)$ \\
\hline & Owning & 9689 & 467 & & & 3164 & 1151 & & \\
\hline & $\mathrm{Bad}$ & 2611 & 338 & 3.54 & $(3.08,4.08)$ & 1931 & 1002 & 1.98 & $(1.80,2.16)$ \\
\hline & Good & 12014 & 454 & 1 & & 2753 & 862 & & \\
\hline
\end{tabular}

Table 3 Number of individuals (no), number of deaths (d), crude relative risk (RR) with 95\% confidence interval (CI) for each independent variable in relation to age in women

\begin{tabular}{|c|c|c|c|c|c|c|c|c|c|}
\hline \multirow[b]{2}{*}{ Variable } & \multirow[b]{2}{*}{ Level } & \multicolumn{4}{|l|}{$25-59 y$} & \multicolumn{4}{|c|}{$60-74 y$} \\
\hline & & No & $d$ & $R R$ & $95 \% C I$ & No & $d$ & $R R$ & $95 \% C I$ \\
\hline \multirow{5}{*}{$\begin{array}{l}\text { Marital } \\
\text { status } \\
\text { Years of } \\
\text { education }\end{array}$} & Living alone & 2937 & 138 & 1.76 & $(1.44,2.14)$ & 1939 & 562 & 1.43 & $(1.28,1.60)$ \\
\hline & Married/cohabiting & 11893 & 334 & 1 & & 3078 & 672 & 1 & \\
\hline & $<=9 y$ & 5424 & 259 & 2.87 & $(2.19,3.77)$ & 3435 & 927 & 1.56 & $(1.24,1.97)$ \\
\hline & $10-11 \mathrm{y}$ & 5322 & 148 & 1.72 & $(1.28,2.30)$ & 1147 & 231 & 1.16 & $(0.89,1.50)$ \\
\hline & $\begin{array}{l}>11 \mathrm{y} \\
\text { Renting }\end{array}$ & $\begin{array}{l}4084 \\
4811\end{array}$ & $\begin{array}{r}65 \\
201\end{array}$ & 153 & & $\begin{array}{r}435 \\
1010\end{array}$ & 76 & 128 & \\
\hline \multirow{3}{*}{$\begin{array}{l}\text { Housing } \\
\text { tenure } \\
\text { Health } \\
\text { status }\end{array}$} & $\begin{array}{l}\text { Renting } \\
\text { Owning }\end{array}$ & $\begin{array}{r}4811 \\
10019\end{array}$ & $\begin{array}{l}201 \\
271\end{array}$ & 1.53 & $(1.28,1.84)$ & $\begin{array}{l}1919 \\
3098\end{array}$ & $\begin{array}{l}530 \\
704\end{array}$ & 1.28 & $(1.14,1.43)$ \\
\hline & Bad & 2937 & 227 & 3.78 & $(3.15,4.52)$ & 2294 & 734 & 1.89 & $(1.69,2.12)$ \\
\hline & Good & 11893 & 245 & 1 & & 2723 & 500 & & \\
\hline
\end{tabular}


Table 4 Relative risks (RR) with 95\% confidence intervals (CI) in four proportional hazard models controlled for age (continuous) in each stratum including all independent variable sin relation to sex and age



aged 60 to 74 years the crude RR for single living decreased when controlled for the other variables, while there were no changes in $R R$ for flat renting and poor health status.

\section{Discussion}

The main finding of the present study was that self reported poor health was strongly associated with increased mortality when simultaneously controlled for important socioeconomic variables such as educational status, type of housing tenure, marital status, and age. Another finding of interest was the tendency of a graded relation between the level of educational attainment and mortality for men and women aged 60 to 74 years.

The advantages of this study were the well defined study population, the follow up time, the low drop out rate, and the response rate of almost $85 \%$. Another strength was the focus on a large random sample of the Swedish population. In this study it was possible to control simultaneously for variables such as age, self reported health status, educational level, type of tenure, and marital status. The number of cases was large enough to analyse data separately in relation to sex and two age groups.

This type of survey has a long tradition and there is therefore a considerable amount of experience associated with it. The questions were well validated and have been consistent over the years, according to Lindström, ${ }^{16}$ and they have a high reliability. ${ }^{17}$ The questions were constructed to give an objective description of the living conditions in Sweden.

Crude RR changed in different age groups when all variables were tested simultaneously in the final models. There were few changes in the older age group, but the crude RR for living alone decreased by about $15 \%$. The association between education and mortality in ages 25 to 59 years could partly be explained by the other variables, but the lowest educational level was still significant in the final model. The strong crude RR for people with bad health status decreased considerably, but remained high in the final model.

The finding of high mortality among those respondents who reported poor health con- curred with a study from Alameda County ${ }^{18}$ and a national survey in the USA, ${ }^{19}$ which showed that self rated poor health (the same question used in the present study) was a powerful predictor of mortality. Data from the national health examination survey epidemiological follow up study, which followed 6440 respondents aged 25-74 years, showed that over a 12 year period poor self rated health was associated with mortality among middle aged men, but not among elderly men or women of any age. ${ }^{19}$ In the present study poor health status was a predictor for mortality with an RR above 2 for men and women aged 25 to 59 years, and a little below 2 in the older age group. The age adjusted RR for mortality from all causes for those who perceived their health as poor as opposed to excellent were 2.3 for men and 5.1 for women using data from 6928 adults in Alameda County in 1965 and a subsequent nine year follow up. ${ }^{18}$

Health and illness are two important variables in epidemiology, but they are extremely difficult to define and there are no valid and universally accepted definitions of either concept. We believe that in a society such as Sweden it might be possible to identify several views of health and illness depending on the individual sociocultural context. There are three important concepts of ill health which need to be defined - disease, illness, and sickness. Disease is defined as the professional dimension of ill health. Physicians use signs based on objective indices of biological structure or function to decide whether disease is present or absent, regardless of whether the individual feels ill at all. Macintyre ${ }^{20}$ found three main problems with this objective view of disease. Firstly, it is difficult to develop universally valid norms of physical functioning because of the range of variability among humans. What is normal for one individual may not be for another, and normality varies with age, sex, sociocultural context, and circumstances. Secondly, indices of disease may have little relationship to subjective experiences of pain, distress, and debility. Thirdly, objective disease may be so prevalent that most of the population would be defined as diseased. In contrast, the concept of illness is focused on 
the individual's subjective dimension of ill health and on the diffuse consequences of the disease process. The association between disease and illness is highly complex and is influenced by a great many social, cultural, and psychological factors. It is possible to feel ill without having a disease, or to be diseased without feeling ill. It is much more common to be diseased without feeling ill than vice versa. By using a large random sample, this study showed that there was an important association between illness (self reported poor health) and disease (mortality) when marital status and indicators of low socioeconomic position were controlled for.

Other studies have focused on particular dimensions of the concept of self rated health, such as functional ability among elderly people. $^{2122}$ The findings of a strong association between poor self rated health and mortality for men and women aged 60 to 74 concurred with a four year follow up study in France of 645 people aged 60 and over. Self rated poor health and disability were associated with odds ratios of 3.9 and 7.8 respectively for mortality. ${ }^{23}$ However, the present study was not focused on disability among older people.

In the present study the level of educational attainment was used as a proxy for social class because education mostly remains unaffected over time while socioeconomic group based on occupation might change because of poor health or unemployment. The finding that men and women aged 25 to 59 with a low level of education had $20 \%$ and $42 \%$ higher mortality respectively than those with a high level of attainment concurred with another European study. ${ }^{24}$ Mortality among middle aged men in Denmark, Sweden, Norway, Finland, England and Wales, and Hungary diminished in a similar way by about $8 \%$ with an increase of one year in educational attainment. ${ }^{25}$ Vågerö and Lundberg, ${ }^{25}$ by constructing a measure of social class very similar to that used in England, found that age standardised death rates for men aged 20-64 were $27 \%$ higher among semiskilled and unskilled workers than among professionals and the managerial groups.

Renting an apartment (not owner occupied) could be used as a crude proxy for lower socioeconomic position. Non-owner occupation generally reflects lack of wealth as well as low income. It has been stated by Macintyre that "over and above individual level attributes of deprivation, people of low socioeconomic status may have poorer health because they tend to live in areas which in some ways are health damaging." 26 People living in residential areas with owner occupied single family homes had more frequent contact with neighbours, regardless of social group. ${ }^{27}$ Private housing areas were occupied by people with good resources, able to influence their environment solely through the form of tenure. There was less migration here and neighbourly contacts were good. Such conditions give a freedom of action which is good for health. ${ }^{27}$ The form of tenure was considered an important factor in relation to explaining health differences. ${ }^{28}$ The residential area with non-owner occupied apart- ments had the highest share of immigrants, manual workers, single parents, and the unemployed, and was also found to have the highest consultation rate at the primary health care centre and the longest duration of visits to the doctor. ${ }^{28}$ These results concur with the finding in the present study of higher mortality for people living in rented apartments.

The finding that living alone was a strong predictor for mortality of all causes for both sexes was in agreement with other studies where convincing evidence of a causal association between social network and mortality have been shown. ${ }^{2930}$

In conclusion, a large random sample of almost 40000 people showed that poor self reported health is a good predictor of death when controlled for age, low socioeconomic position, and marital status. There were class differences in health in Swedish society during the $1980 \mathrm{~s}$, which tended to show a graded dose-response association between the level of educational attainment and mortality. Furthermore, men and women not living in owner occupied homes had higher mortality.

This work was supported by grants from Swedish Medical Research Council grant no K95-21P-11333-01A, Swedish Council for Social Research grant no 94-0048:2B and The Swedish Society of Medicine.

1 Östlin P. Occupational career and health. Methodological considerations on the healthy worker effect. Uppsala: University of Uppsala 1989. (Dissertation)

2 Thorslund $M$, Wärneryd B. Methodological research in the Swedish surveys of living conditions. Social Indicators Research 1985;16:77-95

3 Vogel J, Andersson LG, Davidsson U, Häll L. Inequality in Sweden. Trends and current situation. Living Conditions 1975-85. Stockholm: Statistics Sweden, 1988. Report No 58.

4 Townsend P, Davidson N. Inequalities in health: the Black report. Harmondsworth: Penguin Books Ltd, 1982.

5 Blaxter M. Evidence on inequality in health from a national survey. Lancet 1987;ii:30-3.

6 Whitehead M. The health divide. Harmondsworth: Penguin, 1987.

7 Delamothe T. Social inequalities in health. BMF 1991;303: 1046-50.

8 Sundquist J. Ethnicity, social class and health. A populationbased study of social factors' influence on self-reported long-term illness, illness incidence, working impairment and disability in 223 Latin American refugees, 333 Finnish and 126 South European labour migrants and $841 \mathrm{sex}-$, age- and education-matched Swedish controls. Soc Sci Med 1995;40(6):777-87.

9 Vågerö D, Norell SE. Mortality and social class in Sweden - Exploring a new epidemiological tool. Scand $\mathcal{F}$ Soc Med 1989;17:49-58.

10 Leon, DA, Vảgerö D, Olausson P. Social class differences in infant mortality in Sweden: comparison with England and Wales. BMF 1992;305:687-691.

11 Rosengren A, Wedel H, Wilhelmsen L. Coronary heart disease and mortality in middle aged men from different occupational classes in Sweden. BMF 1988;297:14971500.

12 Valkonen T, Martelin T, Rimpelä A, Notkola V, Savela S. Socio-economic mortality differences in Finland 1981-90. Population. Helsinki: Statistics Finland, 1993; 1

13 Welin L, Tibblin G, Svärdsudd K. et al. Prospective study of social influences on mortality. Lancet 1985;i:915-18.

14 Cox DR and Oakes D. Analysis of survival data. London: Chapman and Hall, 1984

15 Qvist J. Livslängden i Sverige (Life expectancy in Sweden 1981-1990) (In Swedish with an English summary), Stockholm: Statistics Sweden, 1992. Demographic Report 1992:3.

16 Lindström H. Non-response errors in sample surveys. Stockholm: Statistics Sweden, 1983.

17 Wärneryd B. Levnadsförhållanden. Återintervjustudie i undersökningen av levnadsförhällanden (ULF) 1989. (In Swedish Living conditions. Reinterviews in ULF 1989). Stockholm: Statistics Sweden, 1991. Appendix 12.

18 Kaplan GA, Camacho T. Perceived health and mortality: a nine-year follow-up of the human population laboratory cohort. Am f Epidemiol 1983;117:292-304.

19 Idler EL, Angel RJ. Self-rated health and mortality in the 
NHANES-I epidemiologic follow-up study. Am $\mathcal{f}$ Public Health 1990;80:446-52.

20 Macintyre S. Health and illness. In: Burgess RG, ed. Key variables in social investigation. London: Routledge \& Kevariables in social investigation. London: Routledge \& Ke-

21 gan Paul, 1986.

mealth and mortality among the elderly in New Haven, Connecticut, and Iowa and Washington Counties, Iowa, 1982-1986. Am f Epidemiol 1990;131:91-103.

22 McCallum J, Shadbolt B, Wang D. Self-rated health and survival: A 7-year follow-up study of Australian elderly. Am $\mathcal{f}$ Public Health 1994;84:1100-05.

23 Grand A, Grosclaude P, Bocquet H, Albarede JL. Disability, psychosocial factors and mortality among the elderly in rural French population. $\mathcal{F}$ Clin Epidemiol 1990;43:773-82

24 EV Valkonen T. Adult mortality and level of education: a comparison of six countries. In:Fox J, ed. Health inequalities in European countries. Gower, Aldershot 1989:142-62.
25 Vågerö $\mathrm{D}$, Lundberg $\mathrm{O}$. Health inequalities in Britain and Sweden. Lancet 1989;i:35-6.

26 Macintyre S, Maciver S, Sooman A. Area, class and health: should we be focusing on places or people? fournal of should we be focusing on places
Social Policy 1993;22(2):213-34.

27 Diderichsen F. Omflyttning, boende och hälsa. (Migration, housing and health. In Swedish with an English summary.) Uppsala: University of Uppsala, 1981. (Dissertation).

28 Sundquist J, Rosén U, Lindén AL, Scherstén B. The influence of social and ethnic segmentation on consultation in primary health care. Scandinavian fournal of Social Welfare 1994;3;19-23.

29 Berkman LF, Syme SL. Social networks, host resistance, and mortality: A nine-year follow-up study of Alamed county residents. Am $\mathcal{F}$ Epidemiol 1979;109:186-204.

30 Orth-Gomér K, Johnson JV. Social network interaction and mortality. A six-year follow-up study of a random sample of the Swedish population. $\mathcal{f}$ Chron Dis 1987;40:949-57. 